\title{
Insights for Care: The Healthcare Utilisation and Cost Impact of Managing Type 2 Diabetes-Associated Microvascular Complications
}

\author{
David Chapman · Roland Foxcroft · Laura Dale-Harris • \\ Hanno Ronte $\cdot$ Farid Bidgoli $\cdot$ Srikanth Bellary
}

Received: October 26, 2018 / Published online: February 8, 2019

(C) The Author(s) 2019

\section{ABSTRACT}

Introduction: The increasing prevalence of type 2 diabetes (T2DM) in the UK imposes a significant burden on the National Health Service (NHS). Despite the availability of effective treatments, the loss of glycaemic control over time results in significant comorbidities, including nephropathy, neuropathy and retinopathy. The cost of treating these

Enhanced digital features To view enhanced digital features for this article go to https://doi.org/10.6084/ m9.figshare.7392761.

Electronic supplementary material The online version of this article (https://doi.org/10.1007/s13300018-0548-4) contains supplementary material, which is available to authorized users.

D. Chapman · R. Foxcroft $\cdot$ H. Ronte

Monitor Deloitte, London, UK

L. Dale-Harris

Social Finance Ltd., London, UK

F. Bidgoli

Merck Sharp and Dohme Limited, Hoddesdon, UK

S. Bellary $(\bowtie)$

Heart of England NHS Foundation Trust, Birmingham, UK

e-mail: srikanth.bellary@heartofengland.nhs.uk

S. Bellary

School of Life and Health Sciences, Aston

University, Birmingham, UK microvascular complications has not been well documented, and this study aimed to provide an accurate assessment of the healthcare resource utilisation (HCRU) associated with managing T2DM and its complications.

Methods: This retrospective cohort study utilised electronic medical records from patients with T2DM from the Heart of England Foundation Trust (HEFT), which captures data from patients using secondary care services. Patients were diagnosed with microvascular complications based on ICD-10 or OPCS codes. HCRU over a 2-year period was based on NHS Tariffs for healthcare services for inpatient, accident and emergency, and dialysis clinic usage.

Results: The study cohort comprised 26,629 patients with T2DM who used HEFT services during the study period, $22.6 \%, 20.8 \%$ and $3.1 \%$ of whom had comorbid nephropathy, retinopathy or neuropathy, respectively. While the prevalence of diabetes in the overall HEFT population was reported to be $7 \%$ in 2012 , diabetes and its associated complications accounted for more than $30 \%$ of secondary care costs. Furthermore, while patients with diabetes represent only $17 \%$ of HEFT inpatients, they account for more than $20 \%$ of service usage. The economic burden of microvascular complications increased substantially with the severity of the condition, with the overall cost exceeding $£ 70$ million over the 2-year period.

Conclusion: This study of patients with T2DM in a typical secondary care provider in the UK 
showed that avoiding the progression of microvascular complications could provide substantial cost savings through targeted interventions that improve outcomes and lower resource use.

Funding: Merck Sharp \& Dohme Limited.

Keywords: Diabetic complications; Healthcare resource utilisation; Insights for care; Microvascular complications; Nephropathy; Neuropathy; Real world data; Retinopathy; Type 2 diabetes

\section{INTRODUCTION}

Type 2 diabetes mellitus (T2DM) accounts for approximately $90 \%$ of all diabetes cases, thereby contributing extensively to the burden that diabetes imposes on individuals and healthcare systems $[1,2]$. This burden is exacerbated by the increasing prevalence of diabetes, driven largely by high rates of obesity and an ageing population $[3,4]$. In the UK, around 700 new cases of T2DM are diagnosed each day, representing a considerable challenge to the National Health Service (NHS) $[5,6]$. In 2010, the estimated cost of T2DM in the UK was approximately $£ 21.8$ billion ( $£ 8.8$ billion in direct costs and $£ 13$ billion in indirect societal costs), a figure that is projected to rise to $£ 36$ billion ( $£ 15.1$ billion in direct costs, $£ 20.5$ billion in indirect costs) by 2035 [7]. The high prevalence of co-morbidities in the population with diabetes [8] and complications related to the disease [7] account for a substantial proportion of this expenditure.

Despite the availability of a number of effective pharmacological treatments, glycaemic control deteriorates over time, and the resulting hyperglycaemia can result in microvascular complications that include such conditions as diabetic nephropathy, neuropathy and retinopathy [9]. Microvascular complications are among the most common comorbidities associated with diabetes, and microalbuminuria has been demonstrated to occur in up to $26.7 \%$ of new patients with diabetes diagnosed in general practice [10]. Although the economic consequences of T2DM are well documented, the contribution of long- term microvascular complications towards overall costs of care is poorly documented.

The Insights for Care database captures pseudonymised (non-identifiable) patient-level clinical and administrative data and prescribing information from 16 distinct data sets from multiple settings of care (primary, secondary, tertiary, and community care and community pharmacy) for approximately one million residents covered by the Heart of England Foundation Trust (HEFT). Data are collected quarterly from all healthcare providers within the Trust, and refreshed on an ongoing basis, to extend the cohort longitudinal record and include newly diagnosed patients. The database links all pertinent social, healthcare intervention, economic and clinical outcome data, thus allowing for a patient's entire pathway to be captured and collated across various care settings over time, and provides a more comprehensive coverage of patient activity than existing research data sets in the UK (e.g. secondary care data set, Hospital Episode Statistics (HES) or primary care data set, Clinical Practice Research Datalink).

As of April 2016, Insights for Care had captured over 93,000 patients with diabetes who had used HEFT secondary care services, with an additional 136,000 patients from the West Midlands region who had used tertiary retinopathy screening services at HEFT, but secondary care services at other NHS hospital trusts [11]. This article presents the findings of a study using the Insights for Care database that aims to provide an accurate assessment of the healthcare resource usage associated with managing T2DM and its microvascular complications.

\section{METHODS}

This retrospective, observational cohort study included patients with T2DM who had used HEFT services between 2010 and 2015 and had a minimum of 2 years' data records, as well as subsets of patients diagnosed with microvascular complications. Patients were selected for cohort inclusion via ICD-10/Office of Population Censuses and Surveys (OPCS) diagnoses 
$[12,13]$ (see Appendix B), and procedure and pathology readings collated from inpatient or outpatient electronic medical records. The study did not require informed consent, since it uses only pseudonymised data. However, research ethics approval was obtained from the National Research Ethics Service South East England-Surrey (Reference 15/LO/0623).

To control for confounding factors that might change over time, analyses were conducted in time-delimited cohorts of the T2DM population. The index date for eligible patients in each microvascular complication cohort was based on the date of the earliest microvascular complication diagnosis during the period between September 2010 and 2012. The cohorts included only those patients with a minimum of 2 years of data prior to and after the index date, in order to maintain consistency over a fixed timeframe for each individual. For each cohort with a microvascular complication, a comparator cohort was created consisting of patients with T2DM without a diagnosis of the same complication before or during the 2-year period. To enable comparison of costing periods, the median index date of the complication cohort was taken as the start of the 2-year costing period for the non-complication group. Patients having a fatal event within the study period were included in the analysis to provide a fuller account of the real-world cost.

Healthcare resource utilisation (HCRU) was expressed in terms of the cost of healthcare services to the payer (NHS), in the linked admitted patient, accident and emergency (A\&E), and dialysis clinic data. Overall costs were estimated using a NHS National Tariff to allow generalizability across the NHS [14]. To achieve this, the 2014/2015 National Tariff Grouper was used to attach core and unbundled healthcare resource groups to HEFT Secondary Uses Service (SUS) data sets for inpatient, outpatient and A\&E activity. Additionally, HEFT nephrology clinic data were used to estimate dialysis costs not captured within SUS data, using the NHS Best Practice Tariff as a representative dialysis episode cost. The costs reflect the cost of all secondary-care activity, including those activities not typically captured in NHS Tariff analyses (e.g. dialysis, diabetic foot amputation and high-cost drugs).

HCRU and costs were obtained for patients with T2DM without microvascular complications, and for those with moderate or severe complications, as defined by ICD-10 codes, OPCS codes, Public Health England Diabetic Eye Screening Grade scores and estimated glomerular filtration rate (eGFR) readings (Appendices A and B [12]; Appendix C [13]). The number of patients with T2DM using healthcare resources was expressed as a proportion of all patients using HEFT in the same year (derived from analysis of the HES data $\operatorname{set}^{1}$ ). Statistical tests for differences between groups were conducted using the Chi-square test with Cramer's $V$ test for strength, performed as post hoc for categorical variables $\left(\phi_{\mathrm{c}}<0.1\right.$ considered to be not significant), and Mann-Whitney-Wilcoxon test ( $U$ test) for numerical variables ( $p$ value of $\leq 0.05$ considered to be significant).

\section{RESULTS}

The analyses in this paper are based on 26,629 patients with T2DM and complete medical records who used HEFT services during the study period. The baseline characteristics of the individual cohorts of those patients with diabetic complications identified in the Insights for Care database are shown in Tables 1, 2 and 3 and included 6021 (22.6\%) with nephropathy (defined by ICD10 codes and eGFR readings, see appendix for details), 824 (3.1\%) with neuropathy and 5526 (20.8\%) with retinopathy. Compared with patients with no complications, patients with moderate and severe nephropathy tended to be older and had diminished renal function (Table 1). Patients with neuropathy had similar characteristics to those with nephropathy (Table 2), while patients with moderate and severe retinopathy tended to

\footnotetext{
1 Copyright (C) 2012, Re-used with the permission of the Health and Social Care Information Centre. All rights reserved.
} 
Table 1 Patient demographics for the cohort with nephropathy $(n=6021)$

\begin{tabular}{|c|c|c|c|c|}
\hline Patient characteristics & $\begin{array}{l}\text { Patients } \\
\text { without } \\
\text { nephropathy }\end{array}$ & $\begin{array}{l}\text { Patients with } \\
\text { moderate } \\
\text { nephropathy }\end{array}$ & $\begin{array}{l}\text { Patients with } \\
\text { severe nephropathy }\end{array}$ & $\begin{array}{l}\text { Comparison of patients } \\
\text { with severe vs no } \\
\text { nephropathy }\end{array}$ \\
\hline Number of patients (\%) & $13,307(68.8)$ & $4996(25.8)$ & $1025(5.3)$ & - \\
\hline $\begin{array}{l}\text { Median (IQR) age at } \\
\text { index date (years) }\end{array}$ & $61(51-72)$ & $75(67-81)$ & $70(59-79)$ & $p<0.001^{\mathrm{a}}$ \\
\hline Gender (\% male) & 53 & 48 & 52 & $\mathrm{NS}\left(\phi_{\mathrm{c}}<0.1\right)^{\mathrm{b}}$ \\
\hline Ethnicity (\% White) & 63 & 77 & 64 & $\mathrm{NS}\left(\phi_{\mathrm{c}}<0.1\right)^{\mathrm{b}}$ \\
\hline Ethnicity (\% South Asian) & 29 & 15 & 29 & $\mathrm{NS}\left(\phi_{\mathrm{c}}<0.1\right)^{\mathrm{b}}$ \\
\hline Ethnicity (\% other) & 8 & 8 & 7 & $\mathrm{NS}\left(\phi_{\mathrm{c}}<0.1\right)^{\mathrm{b}}$ \\
\hline $\begin{array}{l}\text { Median (IQR) time since first } \\
\text { diagnosis of diabetes in secondary } \\
\text { care (years) }\end{array}$ & $2(1-4)$ & $2(2-6)$ & $2(1-4)$ & $p<0.001^{\mathrm{a}}$ \\
\hline Median (IQR) $\mathrm{HbA}_{1 \mathrm{c}}(\mathrm{mmol} / \mathrm{mol})$ & $7.1(6.6-8.1)$ & $7.1(6.6-8.0)$ & $7.3(6.6-8.4)$ & $p=0.006^{\mathrm{a}}$ \\
\hline Median (IQR) cholesterol $(\mathrm{mmol} / \mathrm{L})$ & $4.2(3.6-4.9)$ & $4.0(3.4-4.7)$ & $4.1(3.5-4.9)$ & $p=0.022^{\mathrm{a}}$ \\
\hline $\begin{array}{l}\text { Median (IQR) eGFR } \\
\left(\mathrm{mL} / \mathrm{min} / 1.73 \mathrm{~m}^{2}\right)\end{array}$ & $87(75-90)$ & $55(46-67)$ & $37(24-86)$ & $p<0.001^{\mathrm{a}}$ \\
\hline $\begin{array}{l}\text { Median (IQR) ACR ratio } \\
\quad(\mathrm{mg} / \mathrm{mmol})\end{array}$ & $1.4(0.7-3.5)$ & $2.4(1.1-6.8)$ & $3.7(1.3-11.1)$ & $p<0.001^{a}$ \\
\hline
\end{tabular}

$A C R$ urinary albumin to creatinine ratio, $e G F R$ estimated glomerular filtration rate, $H b A_{I C}$ glycosylated haemoglobin, IQR interquartile range, $N S$ no significant difference

a Assessed using the Mann-Whitney $U$ test

b Assessed using the Chi-square test with Cramer's $V$ test for strength

have been treated in secondary care for longer (Table 3).

\section{HCRU}

While the prevalence of diabetes in the overall HEFT population was reported to be 7\% in 2012 [15], the HCRU attributable to diabetes was higher, accounting for an estimated $31 \%$ of secondary care costs (Fig. 1), as patients with diabetes were more likely to be hospital users, tended to present more frequently and received more intensive care. Furthermore, while patients with diabetes represented only $17 \%$ of HEFT inpatients, they accounted for more than $20 \%$ of service usage and costs across all top 10 treatment specialities in inpatient care (Fig. 2a).
For some specialities, such as cardiology and general medicine, the share of costs for patients with T2DM was almost half of the total cost for HEFT (Fig. 2b). Among the patients with diabetes who used HEFT services during the study period, $22.6 \%, 20.8 \%$ and $3.1 \%$ of patients had comorbid nephropathy, retinopathy or neuropathy, respectively; together, these microvascular complications incurred more than $£ 72$ million in costs within the 2 years immediately post diagnosis.

\section{Cost of Nephropathy}

In the cohort of patients with T2DM and nephropathy, increased severity was associated with both an increased frequency of 
Table 2 Patient demographics for the cohort with neuropathy $(n=824)$

\begin{tabular}{|c|c|c|c|c|}
\hline Patient characteristics & $\begin{array}{l}\text { Patients } \\
\text { without } \\
\text { neuropathy } \\
(n=23,395)\end{array}$ & $\begin{array}{l}\text { Patients with } \\
\text { moderate } \\
\text { neuropathy } \\
(n=793)\end{array}$ & $\begin{array}{l}\text { Patients with } \\
\text { severe neuropathy } \\
(n=31)\end{array}$ & $\begin{array}{l}\text { Comparison of patients } \\
\text { with severe vs no } \\
\text { neuropathy }\end{array}$ \\
\hline Number of patients (\%) & $23,395(96.6)$ & $793(3.3)$ & $31(0.1)$ & - \\
\hline $\begin{array}{l}\text { Median (IQR) age at } \\
\text { index date (years) }\end{array}$ & $67(56-77)$ & $70(59-79)$ & $63(51-72)$ & NS $(p>0.05)^{a}$ \\
\hline Gender (\% male) & 51 & 49 & 68 & $\mathrm{NS}\left(\phi_{\mathrm{c}}<0.1\right)^{\mathrm{b}}$ \\
\hline Ethnicity (\% white) & 69 & 79 & 87 & $\mathrm{NS}\left(\phi_{\mathrm{c}}<0.1\right)^{\mathrm{b}}$ \\
\hline Ethnicity (\% South Asian) & 23 & 17 & 6 & $\operatorname{NS}\left(\phi_{\mathrm{c}}<0.1\right)^{\mathrm{b}}$ \\
\hline Ethnicity (\% other) & 8 & 4 & 7 & $\operatorname{NS}\left(\phi_{\mathrm{c}}<0.1\right)^{\mathrm{b}}$ \\
\hline $\begin{array}{l}\text { Median (IQR) time since first } \\
\text { diagnosis of diabetes in secondary } \\
\text { care (years) }\end{array}$ & $2(2-5)$ & $3(2-4)$ & $3(1-4)$ & $p<0.001^{a}$ \\
\hline Median (IQR) $\mathrm{HbA}_{\mathrm{lc}}(\mathrm{mmol} / \mathrm{mol})$ & $7.1(6.6-8.1)$ & $7.4(6.5-8.5)$ & $7.7(6.8-9.9)$ & $\mathrm{NS}(p>0.05)^{\mathrm{a}}$ \\
\hline Median (IQR) cholesterol $(\mathrm{mmol} / \mathrm{L})$ & $4.1(3.5-4.8)$ & $4.0(3.4-4.8)$ & $3.8(3.5-4.3)$ & NS $(p>0.05)^{\mathrm{a}}$ \\
\hline $\begin{array}{l}\text { Median (IQR) eGFR } \\
\quad\left(\mathrm{mL} / \mathrm{min} / 1.73 \mathrm{~m}^{2}\right)\end{array}$ & $86(64-90)$ & $76(56-90)$ & $87(58-90)$ & $\mathrm{NS}(p>0.05)^{\mathrm{a}}$ \\
\hline $\begin{array}{l}\text { Median (IQR) ACR ratio } \\
\quad(\mathrm{mg} / \mathrm{mmol})\end{array}$ & $1.7(0.9-4.4)$ & $2.1(1.0-5.9)$ & $4.4(1.7-35.3)$ & $p=0.036^{a}$ \\
\hline
\end{tabular}

$A C R$ urinary albumin to creatinine ratio, $e G F R$ estimated glomerular filtration rate, $H b A_{1 C}$ glycosylated haemoglobin, IQR interquartile range, $N S$ no significant difference

a Assessed using the Mann-Whitney $U$ test

b Assessed using the Chi-square test with Cramer's $V$ test for strength

interactions with HEFT (Fig. 3) and a longer duration of inpatient stay, with an average of 19 inpatient episodes at a nephrology department within 2 years of diagnosis. Activity levels for the 133 patients receiving haemodialysis were substantially higher, with an average of 140 dialysis-related attendances at HEFT over the 2 years post-index date. Inpatient interactions were subject to the greatest increase in frequency between patients without nephropathy and patients with severe nephropathy (1.1 events versus 20.9 events over a 2-year period, respectively), compared with outpatient interactions (5.6 versus 13.1 events, respectively) and $A \& E$ interactions (1.0 versus 2.0 events, respectively). This increase in HCRU led to increased costs for both inpatient and outpatient visits with the annual cost per patient increasing in proportion to the severity of the condition, and costs for patients with severe nephropathy $(£ 2765)$ being almost seven times those of the patients with no complications (Fig. 4).

\section{Cost of Neuropathy}

Severity of neuropathy in patients with T2DM was similarly associated with an increased frequency and length of interaction with HEFT, with an average of 11 interactions over a 2-year period (no neuropathy) rising to 50 (severe neuropathy) (Fig. 3). This led to an increase in costs for both inpatient and outpatient visits, where the annual cost per patient was shown to 
Table 3 Patient demographics for the cohort with retinopathy $(n=5526)$

\begin{tabular}{|c|c|c|c|c|}
\hline Patient characteristics & $\begin{array}{l}\text { Patients } \\
\text { without retinopathy } \\
(n=15,396)\end{array}$ & $\begin{array}{l}\text { Patients with } \\
\text { moderate } \\
\text { retinopathy } \\
(n=4101)\end{array}$ & $\begin{array}{l}\text { Patients with } \\
\text { severe } \\
\text { retinopathy } \\
(n=1425)\end{array}$ & $\begin{array}{l}\text { Comparison of } \\
\text { patients } \\
\text { with severe vs no } \\
\text { retinopathy }\end{array}$ \\
\hline Number of patients (\%) & $15,396(73.6)$ & $4101(19.6)$ & $1425(6.8)$ & - \\
\hline Median (IQR) age at index date (years) & $64(54-77)$ & $69(59-77)$ & $68(57-77)$ & $p=0.006^{\mathrm{a}}$ \\
\hline Gender ( $\%$ male $)$ & 50 & 53 & 52 & $\mathrm{NS}\left(\phi_{\mathrm{c}}<0.1\right)^{\mathrm{b}}$ \\
\hline Ethnicity (\% white) & 72 & 69 & 59 & NS $\left(\phi_{c}<0.1\right)^{\mathrm{b}}$ \\
\hline Ethnicity (\% South Asian) & 21 & 23 & 33 & NS $\left(\phi_{\mathrm{c}}<0.1\right)^{\mathrm{b}}$ \\
\hline Ethnicity (\% other) & 7 & 8 & 8 & $\mathrm{NS}\left(\phi_{\mathrm{c}}<0.1\right)^{\mathrm{b}}$ \\
\hline $\begin{array}{l}\text { Median (IQR) time since first diagnosis } \\
\text { of diabetes in secondary care (years) }\end{array}$ & $2(1-3)$ & $3(2-7)$ & $3(2-8)$ & $p<0.001^{\mathrm{a}}$ \\
\hline Median (IQR) $\mathrm{HbA}_{\mathrm{lc}}(\mathrm{mmol} / \mathrm{mol})$ & $7.0(6.5-7.8)$ & $7.3(6.6-8.2)$ & $7.7(6.9-8.9)$ & $p<0.001^{\mathrm{a}}$ \\
\hline Median (IQR) cholesterol (mmol/L) & $4.3(3.6-5.0)$ & $3.9(3.4-4.6)$ & $4.0(3.4-4.8)$ & $p<0.001^{\mathrm{a}}$ \\
\hline Median (IQR) eGFR (mL/min/1.73 m²) & $85(65-90)$ & $77(57-90)$ & $75(56-90)$ & $p<0.001^{\mathrm{a}}$ \\
\hline Median (IQR) ACR ratio $(\mathrm{mg} / \mathrm{mmol})$ & $1.7(0.8-4.5)$ & $1.8(0.9-4.5)$ & $2.5(1.0-6.5)$ & $p<0.001^{\mathrm{a}}$ \\
\hline
\end{tabular}

$A C R$ urinary albumin to creatinine ratio, $e G F R$ estimated glomerular filtration rate, $H b A_{1 C}$ glycosylated haemoglobin, $I Q R$ interquartile range, $N S$ no significant difference

a Assessed using the Mann-Whitney $U$ test

b Assessed using the Chi-square test with Cramer's $V$ Test for strength

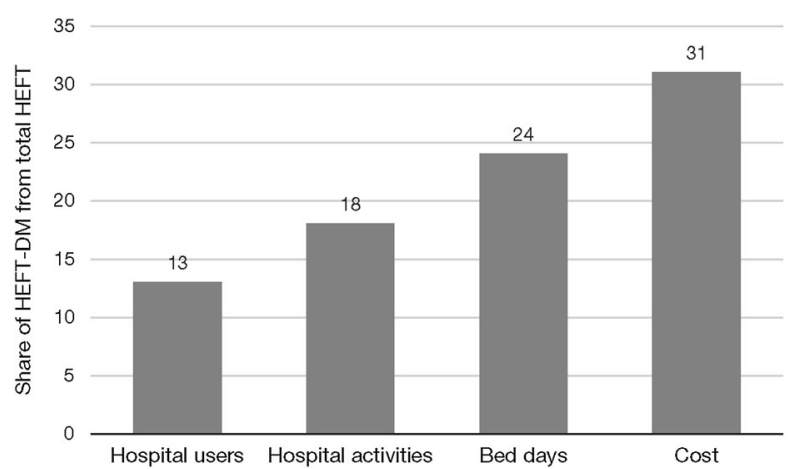

Fig. 1 Healthcare resource utilisation by patients in HEFT with diabetes (HEFT-DM)

be greater for patients with moderate or severe neuropathy compared with patients with moderate or severe nephropathy (Fig. 4). Moreover, the average inpatient and outpatient costs per patient with severe neuropathy were over $£ 8700$-more than 13 times higher than for a patient with no diagnosis of neuropathy within the study timeframe.

\section{Cost of Retinopathy}

Although the number of outpatient appointments per patient increased as retinopathy progressed (median number of outpatient clinic appointments in the 2 years post-index date of 3,5 and 7 for patients with T2DM and no retinopathy, moderate retinopathy or severe retinopathy, respectively), the number and length of stay of inpatient admissions did not differ from patients without retinopathy. However, the number of admissions to the nephrology department (for dialysis) was strongly correlated with retinopathy severity 


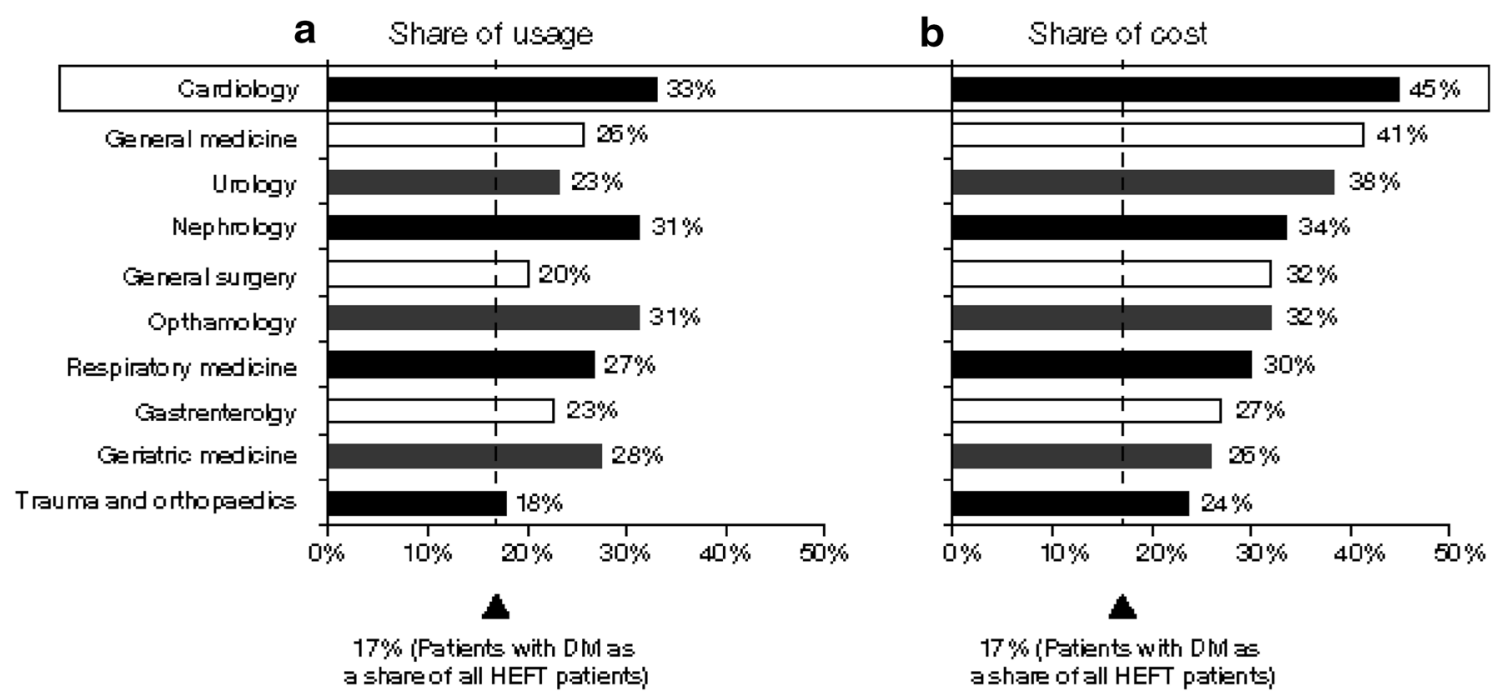

Fig. 2 Comparison of share of $\mathbf{a}$ inpatient usage with $\mathbf{b}$ cost per treatment specialty in patients with T2DM versus all patients in HEFT

(median of $0.9,2.8$ and 6.9 attendances in 2 years for patients with no retinopathy, moderate retinopathy or severe retinopathy, respectively). Accordingly, patients with T2DM with severe retinopathy incurred higher cost per patient (£984) compared with patients with moderate or no retinopathy (Fig. 4).

\section{DISCUSSION}

The main finding of this study was that microvascular complications account for a substantial proportion of HCRU and costs in patients with diabetes and are, therefore, important economic and clinical targets.

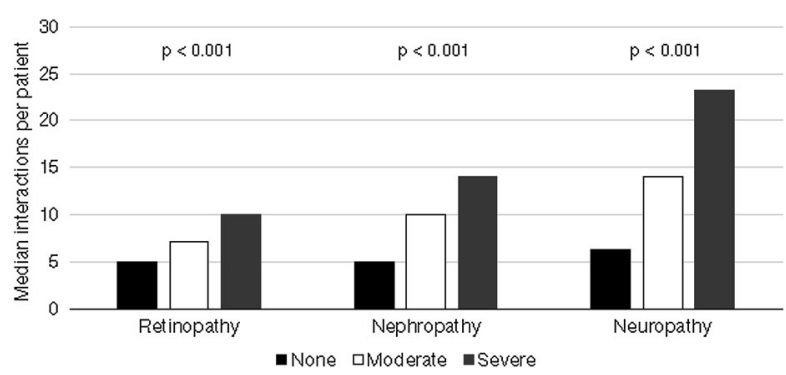

Fig. 3 Frequency of interactions with HEFT per patient for different levels of severity of stages of retinopathy, nephropathy and neuropathy
Crucially, enhanced diabetes care may be capable of preventing their occurrence $[16,17]$. This study also showed that the economic impact of T2DM microvascular complications increases substantially with the severity of the complication. For example, treatment for patients with severe nephropathy accounted for more than a third of average inpatient costs per patient, largely driven by the cost of haemodialysis [18]. Moreover, the average cost for patients with diabetic neuropathy, largely related to diabetic foot ulcer disease [19], was almost twice that of patients with nephropathy.

A previous study also assessed the economic impact of diabetic nephropathy in Germany [20]; while the study was much smaller in scale,

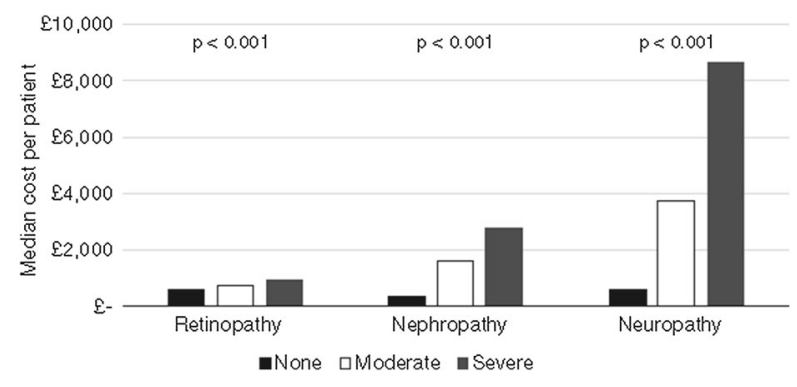

Fig. 4 Estimated cost per patient for different levels of severity of stages of retinopathy, nephropathy and neuropathy 
the findings were consistent with this study, demonstrating higher costs with severe disease, largely driven by costs of dialysis. In the USA, costs have also been shown to rise substantially as nephropathy progresses [21]. There is substantial evidence to show that intensive risk factor management and the early use of nephroprotective agents (e.g. ACE inhibitors, angiotensin receptor blockers) can prevent or delay progression of diabetic nephropathy, and that they are also cost-effective [22]. Our findings confirm the additional burden on healthcare resources due to these complications, and they highlight the importance of identifying and managing these complications in the NHS, as efficiency becomes paramount in this finite system.

While it might be expected that patients with severe nephropathy would incur the highest proportion of inpatient stays in a nephrology department (86.7\%), a similarly high proportion was observed in patients with both severe neuropathy (79.9\%) and severe retinopathy (69.4\%). Again, these data concur with other international reports regarding the burden of neuropathy [23]. Although some of this increase could be due to coexistence of disease (e.g. renal and eye disease are widely recognised to occur together [24]), it also implies that any presentation with one microvascular complication in the outpatient or inpatient setting represents an opportunity to screen for, or assess, other, possibly more serious, microvascular complications. Presentation of neuropathy is varied and certainly during the early stages the methods of screening commonly used are highly subjective. Optimal methods of screening would therefore need to be determined and entered into economic models-for example, electrophysiological screening identifies more cases than questionnaire or scoring tools, but will be more costly [25].

Although the focus of this study is on microvascular complications, the presence of these complications is an indication of associated cardiovascular disease [26], such that risk profiling for macrovascular disease might be equally important in these settings. Our data showed that patients with T2DM use a variety of clinical services (i.e. not just endocrinology), many of which are associated with the management of complications (cardiology, nephrology, ophthalmology, general surgery, trauma and orthopaedics) that account for a significant share of all secondary care activity. It is to be expected that prevention of these complications would further reduce service demand in the inpatient setting but also implies that all such general areas should have access to specialist diabetic services that can assess and manage the patient globally. The proactive assessment of complications other than those that are the primary reason for attendance could be valuable in preventing later admissions.

There are some limitations in this study in that, as diagnosis is undertaken across multiple data sets (including retinopathy), it is likely that the database is more accurate in identifying local diabetes patients than non-local ones. In addition, as the date of first diagnosis is not currently available from primary care, and the date of first diabetes hospital usage is likely to be after diagnosis in many cases, using the date of first diabetes hospital usage as a de facto diagnosis date would likely underestimate the time since true diagnosis of population and may bias the results.

Finally, patients who only use retinopathy screening services (i.e. do not use HEFT core services) are excluded, as retinopathy is not a typical service provision of most major hospital trusts. Indeed, our data showed that, while there was a relatively stable incidence of nephropathy and neuropathy among patients with T2DM between 2010 and 2014, there was a significant decrease in the incidence of retinopathy (Fig. 5). This was possibly due to the high number of retinopathy screenings after the introduction of the Retinopathy Screening Service in 2008, and a subsequent decline in the background incidence rate due to improved disease management.

The variation in patient characteristics, HEFT service utilisation and economic resource usage between groups of patients with or without severe microvascular complications has been assessed for statistical significance using univariate statistical tests. These, therefore, do not 


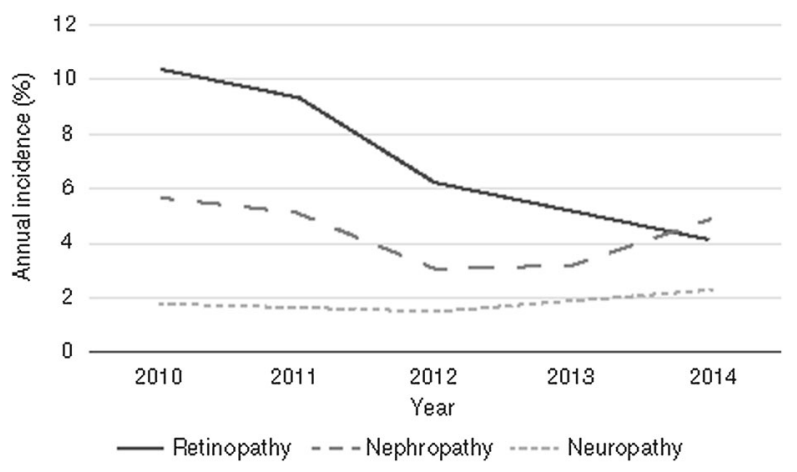

Fig. 5 Annual incidence of retinopathy, nephropathy and neuropathy in HEFT between 2010 and 2014

control for possible confounding characteristics such as age or the presence of other comorbidities, which should be investigated in future work. Additionally, since this study encompasses the vast majority of HEFT patients with diabetes (subject to the limitations discussed above), the relatively large cohort 'sample' sizes (especially for retinopathy) tend to lead to formal statistical significance even when the absolute variation between groups may not be clinically relevant. Clinicians and health policymakers should assess the clinical meaningfulness of variations between groups when considering novel pathway interventions targeted at the patients considered in this study.

\section{CONCLUSION}

This study provides a comprehensive assessment of the burden of microvascular complications in patients with T2DM on a typical, large, secondary care provider in the UK. It is clear that avoiding the progression of microvascular complications in patients with diabetes could provide substantial cost savings. These findings suggest areas where targeted interventions may improve outcomes and lower resource use.

\section{ACKNOWLEDGEMENTS}

We thank all the participants of the study. Data acquisition and analysis was performed by $\mathrm{D}$
Chapman, L Yassa, R Foxcroft, S Song and H Ronte, of Monitor Deloitte, London, UK (funded by Merck Sharp and Dohme Limited, Hoddesdon, UK) and R Das and F Bidgoli of Merck Sharp \& Dohme Limited, Hoddesdon, UK. We also thank Dr Alice Turner, University of Birmingham, for her guidance on the IFC project.

Funding. This study and the article processing charges were funded by Merck Sharp \& Dohme Limited, Hoddesdon, UK. All authors had full access to all of the data in this study and take complete responsibility for the integrity of the data and accuracy of the data analysis.

Editorial Assistance. Editorial support was provided by K Ian Johnson and Mariam Bibi of McCann Health and funded by Merck Sharp and Dohme Limited, Hoddesdon, UK.

Authorship. All named authors meet the International Committee of Medical Journal Editors (ICMJE) criteria for authorship for this article, take responsibility for the integrity of the work as a whole, and have given their approval for this version to be published.

Disclosures. Farid Bidgoli (now based at Roche Iran) was a former employee of Merck Sharp \& Dohme Limited, Hoddesdon, UK and may have owned stock and/or stock options. Srikanth Bellary has received research funds from the Binding site UK Ltd and Novo Nordisk UK Ltd and consultancy and speaker fees from Boehringer Ingelheim, MSD, Takeda, Sanofi Aventis, Eli Lilly, AstraZeneca, Napp and Novo Nordisk. David Chapman, Roland Foxcroft, Laura Dale-Harris and Hanno Ronte have nothing to disclose.

Compliance with Ethics Guidelines. Ethics approval was obtained from the National Research Ethics Service South East EnglandSurrey (Reference 15/LO/0623).

Data Availability. The data sets generated during and/or analyzed during the current study are not publicly available for patient confidentiality reasons, but are available from 
the corresponding author upon reasonable request.

Open Access. This article is distributed under the terms of the Creative Commons Attribution-NonCommercial 4.0 International License (http://creativecommons.org/licenses/ by-nc/4.0/), which permits any noncommercial use, distribution, and reproduction in any medium, provided you give appropriate credit to the original author(s) and the source, provide a link to the Creative Commons license, and indicate if changes were made.

\section{REFERENCES}

1. Holman N, Young B, Gadsby R. Current prevalence of type 1 and type 2 diabetes in adults and children in the UK. Diabet Med. 2015;32(9):1119-20.

2. Evans JM, Newton RW, Ruta DA, MacDonald TM, Morris AD. Socio-economic status, obesity and prevalence of type 1 and type 2 diabetes mellitus. Diabet Med. 2000;17(6):478-80.

3. Kearns K, Dee A, Fitzgerald AP, Doherty E, Perry IJ. Chronic disease burden associated with overweight and obesity in Ireland: the effects of a small BMI reduction at population level. BMC Public Health. 2014;14:143. https://doi.org/10.1186/1471-245814-143.:143-14.

4. International Diabetes Federation. IDF diabetes atlas, 7th edn. IDF: Brussels; 2015.

5. Diabetes UK. The state of the nation: challenges for 2015 and beyond. London: Diabetes UK; 2015.

6. Bennett $\mathrm{H}$, McEwan P, Bergenheim K, Gordon J. Assessment of unmet clinical need in type 2 diabetic patients on conventional therapy in the UK. Diabetes Ther. 2014;5(2):567-78.

7. Hex N, Bartlett C, Wright D, Taylor M, Varley D. Estimating the current and future costs of type 1 and type 2 diabetes in the UK, including direct health costs and indirect societal and productivity costs. Diabet Med. 2012;29(7):855-62.

8. Chapman D, Song S, Foxcroft R, Bidgoli F, Ronte H, Bellary S. Insights for care: using real-world data to quantify diabetes treatment patterns and outcomes in an urban health economy. Value Health. 2016;19(3):A83.
9. Fowler MJ. Microvascular and macrovascular complications of diabetes. Clin Diabetes. 2008;26(2):77-82.

10. Spijkerman AMW, Dekker JM, Nijpels G, et al. Microvascular complications at time of diagnosis of type 2 diabetes are similar among diabetic patients detected by targeted screening and patients newly diagnosed in general practice. Diabetes Care. 2003;26(9):2604-8.

11. Foxcroft R, Chapman D, Yassa L, et al. Insights for Care: building a pseudonymised, linked, crosssetting real-world evidence research alliance in Birmingham. Value Health. 2016;19(3):A211.

12. WHO. International statistical classification of diseases and related health problems, 10th Revision. Geneva: World Health Organization; 2010.

13. UK NHS. OPCS classification of interventions and procedures. 2017. https://www.datadictionary.nhs. uk/web_site_content/supporting_information/ clinical_coding/opcs_classification.

14. NHS England. 2014/15 National tariff payment system. 2018. https://assets.publishing.service.gov.uk/ government/uploads/system/uploads/attachment_ data/file/300547/2014-15_National_Tariff_Payment_ System_-Revised_26_Feb_14.pdf .

15. Diabetes UK. Diabetes prevalence 2012. London: Diabetes UK; 2012.

16. UK Prospective Diabetes Study Group. Tight blood pressure control and risk of macrovascular and microvascular complications in type 2 diabetes: UKPDS 38. UK Prospective Diabetes Study Group. BMJ. 1998;317(7160):703-13.

17. Porath A, Fund N, Maor Y. Costs of managing patients with diabetes in a large health maintenance organization in Israel: a retrospective cohort study. Diabetes Ther. 2017;8(1):167-76.

18. Zhou $\mathrm{Z}$, Chaudhari $\mathrm{P}$, Yang $\mathrm{H}$, et al. Healthcare resource use, costs, and disease progression associated with diabetic nephropathy in adults with type 2 diabetes: a retrospective observational study. Diabetes Ther. 2017;8(3):555-71.

19. Gordois A, Scuffham P, Shearer A, Oglesby A, Tobian JA. The health care costs of diabetic peripheral neuropathy in the US. Diabetes Care. 2003;26(6):1790.

20. Happich M, John J, Stamenitis S, Clouth J, Polnau D. The quality of life and economic burden of neuropathy in diabetic patients in Germany in 2002-results from the Diabetic Microvascular Complications (DIMICO) study. Diabetes Res Clin Pract. 2008;81(2):223-30. 
21. Nichols GA, Vupputuri S, Lau H. Medical care costs associated with progression of diabetic nephropathy. Diabetes Care. 2011;34(11):2374-8.

22. Huang Y, Zhou Q, Haaijer-Ruskamp FM, Postma MJ. Economic evaluations of angiotensin-converting enzyme inhibitors and angiotensin II receptor blockers in type 2 diabetic nephropathy: a systematic review. BMC Nephrol. 2014;15:15.

23. Sadosky A, Mardekian J, Parsons B, Hopps M, Bienen EJ, Markman J. Healthcare utilization and costs in diabetes relative to the clinical spectrum of painful diabetic peripheral neuropathy. J Diabetes Complications. 2015;29(2):212-7.

24. Pugliese G, Solini A, Bonora E, et al. Distribution of cardiovascular disease and retinopathy in patients with type 2 diabetes according to different classification systems for chronic kidney disease: a crosssectional analysis of the renal insufficiency and cardiovascular events (RIACE) Italian multicenter study. Cardiovasc Diabetol. 2014;13:59.

25. Fateh HR, Madani SP, Heshmat R, Larijani B. Correlation of Michigan neuropathy screening instrument, United Kingdom screening test and electrodiagnosis for early detection of diabetic peripheral neuropathy. J Diabetes Metab Disord. 2015;15:8.

26. Li LX, Li MF, Lu JX, et al. Retinal microvascular abnormalities are associated with early carotid atherosclerotic lesions in hospitalized Chinese patients with type 2 diabetes mellitus. J Diabetes Complications. 2014;28(3):378-85. 